\title{
Re-imagining commonly used mobile interfaces for older adults
}

Emma Nicol,

Mark Dunlop,

Andreas Komninos,

Marilyn McGee-Lennon,

The Mobiquitous Lab

Univ. Strathclyde, Glasgow, UK

strathclyde@olderadults.mobi

Lynne Baillie

Interactive \& Trustworthy

Technologies Group

Glasgow Caledonian University, UK

L.Baillie@gcu.ac.uk

Alistair Edwards

York HCI

University of York, York, UK

alistair.edwards@york.ac.uk

Parisa Eslambolchilar

Computer Science Department

Swansea University, Swansea, UK

p.eslambolchilar@swansea.ac.uk

Joy Goodman-Deane

Engineering Design Centre,

Univ. Cambridge, Cambridge, UK

jag76@cam.ac.uk

\section{Lilit Hakobyan,}

Jo Lumsden

Computer Science

Aston University, Birmingham, UK

hakobyl1@aston.ac.uk

\section{Ingrid Mulder}

Industrial Design

Delft University of Technology, NL

I.J.Mulder@tudelft.n

\section{Patrick Rau}

Human Factors \& Ergonomics,

Tsinghua University, Beijing, PRC

rpl@mail.tsinghua.edu.cn

\section{Katie Siek}

Informatics and Computing

Indiana University, USA

ksiek@indiana.edu

Copyright is held by the author/owner(s).

MobileHCI 2014, 23-26 September, 2014, Toronto, Canada.

ACM XXX-X-XXXX-XXXX-X/XX/XX.

\begin{abstract}
Many countries have an increasingly ageing population.

In recent years, mobile technologies have had a massive impact on social and working lives. As the size of the older user population rises, many people will want to continue professional, social and lifestyle usage of mobiles into 70s and beyond. Mobile technologies can lead to increased community involvement and personal independence. While mobile technologies can provide many opportunities, the ageing process can interfere with their use. This workshop brings together researchers who are re-imagining common mobile interfaces so that they are more suited to use by older adults
\end{abstract}

\section{Author Keywords}

Older adults, mobile interface design, inclusive design

\section{ACM Classification Keywords}

H.5.2 User Interfaces.

\section{Background and motivation}

The world population is ageing, with the percentage of older people rising, e.g. adults over 65 are expected to form $39 \%$ of the UK population and $71 \%$ of the

Japanese population by 2050 . Mobile technologies are increasingly important in supporting independent living and social contact. In addition, many healthcare 
solutions are moving away from purpose-built equipment to exploiting mainstream mobiles and tablets for supporting older adults growing older independently. Together these trends open up a wealth of opportunities and challenges to design mobile solutions that are usable by older adults.

The natural ageing processes can make smartphone interaction particularly challenging for older adults. Key recommendations by Fisk et al [6] for designing for this age group are at a complete contrast with typical smartphone touchscreen interactions where:

- Soft buttons require almost zero force to activate and have zero travel;

- Soft keyboards typically have no gap between keys (with visible gaps often being interpreted to keys);

- Surfaces that are high gloss, low friction, glass;

- and Interfaces often have reduced contrast for styling, exacerbated by sunlight and reflections.

This workshop brings together researchers from many disciplines to build a MobileHCI centered community on overcoming issues in mobile interfaces for older adults.

\section{The HCI Design Process with older adults}

Design for ageing involves understanding the diverse and unique capabilities and limitations of older adults identifying their needs, preferences and desires for technology in their lives and involving them in the design process [13]. However, this group brings challenges to design teams, and researchers need to be sensitive to the characteristics, sensory and cognitive capabilities, and the attitudes of older people towards computers and their being included in research studies [5].
In the early work on cultural probes, Gaver et al [7] used probes with older adults to better understand their habits and interests. They found that the technique also provoked the participants to think about the roles they play and the pleasures they experience, and that probes can help to establish a rich conversation between designers and users. Recently, Vines et al [17] called for a more nuanced understanding of how control is shared between researchers and participants, for the initiators and beneficiaries to be more explicitly revealed and for there to be a more reflexive understanding of how participation takes place.

\section{Physical mobile interaction and older adults}

While older adults are, overall, still slower than younger adults when interacting with mobile interfaces, studies (e.g. [4]) have shown that, touchscreens reduce this performance gap when compared to traditional keys and mice. However, the size of on-screen buttons has a clear influence on interaction speed and accuracy (e.g. [10][14]) and dwell times are significantly longer for users with motor-control difficulties [14]. Studies on the effects of tremor in older user text entry showed that omitted letters were the most common error [11]. Encouragingly though, touch models, filters and simple re-designs, e.g. moving touch targets from the edges, can reduce error rates considerably [12].

On the display side, studies have found that age can have a significant impact on navigation and learnability [1], that older users often have difficulty in assessing the function of buttons, can have difficulty understanding mobile scroll bars [9], and that font choice can be a particular issue for this group [2]. 


\section{Opportunities for novel mobile interaction}

Designing interfaces that exploit the wealth of sensors and technologies in modern smartphones and personalizing interaction to different user groups gives great opportunities for better interaction. We have seen that, due to different backgrounds and experiences, older adults can actually be more open to new interaction approaches than young adults, who have more intense use of current mainstream mobile interaction. Even where there is resistance to novel interaction, studies of technology acceptance using mobiles found that tutorial training can significantly affect acceptance outcomes for older users [20].

One major opportunity is to look at how multisensory or multimodal interaction can be best harnessed for this group as a whole and to widen the range of users and range of use-locations. In homecare reminder systems, multimodal notifications have been successfully tested using visual, oral and olfactory modalities [18]. Stößel found that gestural interaction can have benefits over conventional key input for older adults [15].

Design changes that provide environmental support for declining cognitive, perceptual and psychomotor abilities can serve as a powerful intervention for maintaining and improving older adult performance [3] Goodman et al [8] showed that a mobile navigation aid significantly outperformed a paper-based map and that older people derived substantially more benefit than younger users. In a study of the use of tablets to create and share photographs it was demonstrated that even the oldest adult group embraced opportunities to express themselves creatively through digital content production when designed for their needs [19].
Mobile health informatics ( $m$-health) is a growing field in itself. In a study of requirements for reminder systems for tele-care [18], results suggested that developers should design for diversity, context, priorities, autonomy, shared spaces, and optimal care. The use of gaming in rehabilitation is another area of particular growth and challenges that could have considerable impact on the health and wellbeing of older adults (e.g. [16]).

\section{Going forward}

Using mobiles into older life is an increasing need in society in order to support active, socially connected independent living. Current mobile interfaces can pose considerable challenges for older adults but there is a wealth of opportunity to be had from multidisciplinary research focused around older adults. This workshop aims to bring together researchers from a wide range of disciplines to discuss and enhance activities to push this domain forward within the wider MobileHCI community.

\section{Acknowledgements}

The workshop is partly supported by the UK EPSRC Council through project reference EP/K024647/1 on designing mobile text entry for older adults.

\section{References}

[1] Balakrishnan, V. and Yeow, P.H. Texting satisfaction: Does age and gender make a difference. Int. J. Comp. Sci. and Security 1, 1 (2007), 85-96.

[2] Bernard, M., Liao, C.H., and Mills, M. The Effects of Font Type and Size on the Legibility and Reading Time of Online Text by Older Adults. $\mathrm{CHI}$ '01 Extended Abstracts, ACM (2001), 175-176. 
[3] Charness, N. Aging and human performance. Human Factors: The Journal of the Human Factors and Ergonomics Society 50, 3 (2008), 548-555.

[4] Chung, M.K., Kim, D., Na, S., and Lee, D. Usability evaluation of numeric entry tasks on keypad type and age. Int. J. Industrial Ergonomics 40, 1 (2010), 97105.

[5] Dickinson, A., Arnott, J., and Prior, S. Methods for human-computer interaction research with older people. Behaviour \& Information Technology 26, 4 (2007), 343-352.

[6] Fisk, A.D., Rogers, W.A., Charness, N., Czaja, S.J., and Sharit, J. Designing for older adults: Principles and creative human factors approaches. CRC press, 2012.

[7] Gaver, B., Dunne, T., and Pacenti, E. Design: Cultural Probes. interactions 6, 1 (1999), 21-29.

[8] Goodman, J., Gray, P., Khammampad, K., and Brewster, S. Using Landmarks to Support Older People in Navigation. Proc. MobileHCI 2004, Springer Berlin Heidelberg (2004), 38-48.

[9] Gould, J. and Schaefer, M. User Interface Considerations for Older Users. Proceedings of the 10th Annual SIGCSE Conference on Innovation and

Technology in Computer Science Education, ACM (2005), 408-408.

[10] Jin, Z.X., Plocher, T., and Kiff, L. Touch Screen User Interfaces for Older Adults: Button Size and Spacing. Proceedings of the 4th International Conference on Universal Access in Human Computer Interaction: Coping with Diversity, Springer-Verlag (2007), 933-941.

[11] Matero, J. and Colley, A. Identifying Unintentional Touches on Handheld Touch Screen Devices. Proceedings of the Designing Interactive Systems Conference, ACM (2012), 506-509.

[12] Nicolau, H. and Jorge, J. Elderly Text-entry Performance on Touchscreens. Proceedings of the 14th
International ACM SIGACCESS Conference on Computers and Accessibility, ACM (2012), 127-134.

[13] Rogers, W.A. and Fisk, A.D. Toward a psychological science of advanced technology design for older adults. The Journals of Gerontology Series B: Psychological Sciences and Social Sciences 65, 6 (2010), 645-653.

[14] Sesto, M.E., Irwin, C.B., Chen, K.B., Chourasia, A.O., and Wiegmann, D.A. Effect of touch screen button size and spacing on touch characteristics of users with and without disabilities. Human Factors: The Journal of the Human Factors and Ergonomics Society 54, 3 (2012), 425-436.

[15] Stößel, C., Wandke, H., and Blessing, L. Gestural Interfaces for Elderly Users: Help or Hindrance? Proc. 8th International Conference on Gesture in Embodied Communication and Human-Computer Interaction, Springer-Verlag (2010), 269-280.

[16] Uzor, S., Baillie, L., and Skelton, D. Senior Designers: Empowering Seniors to Design Enjoyable Falls Rehabilitation Tools. Proc. SIGCHI Conference, ACM (2012), 1179-1188.

[17] Vines, J., Clarke, R., Wright, P., McCarthy, J., and Olivier, P. Configuring Participation: On How We Involve People in Design. Proc. SIGCHI Conf. Human Factors in Computing Systems, ACM (2013), 429-438.

[18] Warnock, D., McGee-Lennon, M., and Brewster, S. Multiple Notification Modalities and Older Users. Proc. SIGCHI Conference, ACM (2013), 1091-1094.

[19] Waycott, J., Vetere, F., Pedell, S., et al. Older Adults As Digital Content Producers. Proc. SIGCHI Conference, ACM (2013), 39-48.

[20] Wilkowska, W. and Ziefle, M. Which Factors Form Older Adults' Acceptance of Mobile Information and Communication Technologies? Proc. 5th Symposium of the Workgroup Human-Computer Interaction and Usability Engineering of the Austrian Computer Society on HCI and Usability for e-Inclusion, Springer-Verlag (2009), 81-101. 